\title{
Kemampuan Mikroorganisme Efektif dalam Mengolah Limbah Cair Pabrik Spiritus
}

\section{The Effective Microorganisms capability for Waste water treatment of spirit Manufacture}

\author{
H.N. Lestari, P. Kianto Atmodjo*, B.R. Sidharta \\ Fakultas Teknobiologi, Universitas Atma Jaya Yogyakarta, Jl. Babarsari 44 Yogyakarta 55281 \\ E-mail: kianto@mail.uajy.ac.id*Penulis untuk korespondensi
}

Proses produksi suatu industri senantiasa menghasilkan limbah yang harus diolah dengan baik agar tidak membahayakan lingkungan. Pabrik spiritus "X" di Yogyakarta telah mengolah limbah cairnya secara fikokimiawi, namun hasilnya masih kurang baik. Karakteristik limbah pabrik ini adalah berbentuk cair, berwarna hitam, bau, keruh, kandungan BOD 2.978 mg/l dan COD 103.433 mg l, sehingga nilainya sangat jauh di atas baku mutu (Kepmen: 03/men LH/I/1998). Untuk itu perlu dilakukan usaha-usaha mengolah lebih lanjut agar mutu limbah semakin mendekati baku mutu. Salah satu usahanya adalah mengolah lebih lanjut dengan metode biologi.

Pengolahan limbah secara biologi, pada dasarnya memanfaatkan makhluk hidup untuk memakan bahan organik atau anorganik yang terkandung dalam limbah sebagai sumber nutrien. Pengolahan lanjutan limbah cair spiritus menggunakan metode biologis dianggap cocok, dikarenakan limbah ini banyak mengandung bahan nutrien yang bermanfaat bagi pertumbuhan makhluk hidup (Balba et al., 1998). Menurut Sulia (2003) pada pengolahan limbah ini, bahan yang terkandung dalam limbah akan didegradasi oleh makhluk hidup, baik tumbuhan hewan, dan atau mikrobia yang telah ada pada limbah, atau perlu ditambahkan, bahkan dimodifikasi.

Pengolahan limbah secara biologi umumnya memanfaatkan mikrobia. Menurut Sudirdjo et al., (2001), banyak macam mikrobia yang telah digunakan untuk mengolah limbah, bahkan telah diperdagangkan, misal $\mathrm{EM}_{4}$ dan Super-NB. Mikrobia pengolah limbah merupakan mikrobia yang adaptif dan mampu hidup dalam lingkungan yang ekstrim. Mikrobia yang digunakan untuk mengolah limbah dapat satu, dua, atau banyak jenis yang digunakan sekaligus ataupun bertahap.

Mikroorganisme efektif (Effective Microorganims $=E M$ ) merupakan campuran mikrobia alami yang terdiri dari bakteri asam laktat, bakteri fotosintetik, khamir, dan jamur benang (Diver, 2001; Szymanski dan Patterson, 2003), telah digunakan pada percobaan pengolahan limbah pabrik spiritus dalam skala laboratorium. Mikroorganisme efektif merupakan mikrobia yang telah diperdagangkan dengan merek dagang $\mathrm{EM}_{4}$. Percobaan ini menggunakan metode rancangan acak lengkap untuk mengetahui berapa banyak larutan $\mathrm{EM}_{4}(10,20$, dan $30 \mathrm{ml} / \mathrm{l}$ limbah) yang dibutuhkan untuk mengolah limbah. Percobaan di lakukan di Laboratorium Bioindustri Fakultas Teknobiologi Universitas Atma Jaya Yogyakarta.

Hasil pengolah limbah cair menggunakan $\mathrm{EM}_{4}$ dengan waktu tinggal mikrobia dalam limbah selama 6 hari (Tabel 1) diketahui bahwa penurunan nilai COD terbesar pada penggunaan $\mathrm{EM}_{4} 30 \mathrm{ml} / \mathrm{l}$ yaitu turun sekitar 95\% dari $103.400 \mathrm{mg} / \mathrm{l}$ menjadi 6.000 $\mathrm{mg} / \mathrm{l}$. Hal yang sama terjadi pada BOD, yaitu turun sekitar $80 \%$ dari $2,978 \mathrm{mg} / \mathrm{l}$ menjadi 468,3 mg/l. Hasil ini jauh lebih besar dibanding kontrol yang hanya turun sekitar 55\% dari $2.978 \mathrm{mg} / \mathrm{l}$ menjadi $1.306 \mathrm{mg} / \mathrm{l}$, demikian pula COD-nya hanya turun 20\% dari $103.433 \mathrm{mg} / \mathrm{l}$ menjadi $81.233 \quad \mathrm{mg} / \mathrm{l}$. Kemampuan menurunkan BOD dan COD berlawanan dengan jumlah mikrobia yang justru meningkat. Hal ini membuktikan bahwa limbah spiritus dapat digunakan untuk medium pertumbuhan mikrobia dan mikrobia mampu 
memanfaatkan bahan organik yang terdapat dalam limbah spiritus, sehingga menurunkan konsumsi oksigen yang digunakan untuk mengoksidasi bahan-bahan tersebut (Szymanksi dan Peterson, 2003). Kemampuan $\mathrm{EM}_{4}$ dalam menurunkan BOD dan COD limbah spiritus mirip dengan penelitian Pratiwi (2003) pada limbah pabrik roti dan susu, dengan besar penurunan 93\% untuk COD dan $60 \%$ untuk BOD dengan waktu pengolahan 15 hari.

Tabel 1. Kemampuan $\mathrm{EM}_{4}$ dalam mengolah limbah spiritus

\begin{tabular}{|c|c|c|c|}
\hline Penggunaan EM ml/l & Parameter & Hari pertama & Hari keenam \\
\hline \multirow[t]{8}{*}{0} & COD mg/l & 103.433 & 81.233 \\
\hline & BOD mg/l & 2.978 & 1.306 \\
\hline & Nitrat mg/l & 2,82 & 2,84 \\
\hline & Fosfat mg/l & 3.19 & 3.09 \\
\hline & Kalium mg/l & 4,05 & 4,03 \\
\hline & TSS mg/l & 1.067 & 1.133 \\
\hline & $\mathrm{pH}$ & 4,91 & 4,66 \\
\hline & Total mikrobia $108 \mathrm{sel} / \mathrm{ml}$ & 71 & 109.7 \\
\hline \multirow[t]{8}{*}{10} & COD mg/l & 103.433 & 21.733 \\
\hline & BOD mg/l & 2.978 & 943 \\
\hline & Nitrat mg/l & 2,82 & 2,92 \\
\hline & Fosfat mg/l & 3.19 & 3.14 \\
\hline & Kalium mg/l & 4,05 & 3,10 \\
\hline & TSS mg/l & 1.067 & 1,060 \\
\hline & $\mathrm{pH}$ & 4,91 & 3,91 \\
\hline & Total mikrobia $108 \mathrm{sel} / \mathrm{ml}$ & 71 & 162.3 \\
\hline \multirow[t]{7}{*}{20} & COD mg/l & 103.433 & 13.800 \\
\hline & BOD mg/l & 2.978 & 843 \\
\hline & Nitrat mg/l & 2,82 & 2,95 \\
\hline & Fosfat mg/l & 3.19 & 3.21 \\
\hline & Kalium mg/l & 1.067 & 0,967 \\
\hline & $\mathrm{pH}$ & 4,91 & 3,79 \\
\hline & Total mikrobia $108 \mathrm{sel} / \mathrm{ml}$ & 71 & 171,7 \\
\hline \multirow[t]{7}{*}{30} & COD mg/l & 103.433 & 6.000 \\
\hline & BOD mg/l & 2.978 & 468 \\
\hline & Nitrat mg/l & 2,82 & 2,91 \\
\hline & Fosfat mg/l & 3.19 & 2,95 \\
\hline & Kalium mg/l & 1.067 & 0,933 \\
\hline & $\mathrm{pH}$ & 4,91 & 3,43 \\
\hline & Total mikrobia $108 \mathrm{sel} / \mathrm{ml}$ & 71 & 230,7 \\
\hline
\end{tabular}

Kemampuan $\quad \mathrm{EM}_{4} \quad$ menurunkan kebutuhan oksigen seiring dengan penurunan $\mathrm{pH}$ yang terbesar juga pada penambahan $\mathrm{EM}_{4}$ $30 \mathrm{ml}$. Penurunan $\mathrm{pH}$ ini terjadi karena ada aktivitas pembentukan asam-asam organik oleh mikrobia, diantaranya asam laktat oleh Lactobacillus. Menurut Eweis et al., (1998) menyatakan bahwa mikrobia dalam $\mathrm{EM}_{4}$ mampu melakukan aktivitas fermentasi yang menghasilkan senyawa-senyawa organik yang bersifat asam.

Kemampuan $\mathrm{EM}_{4}$ dalam menurunkan kebutuhan oksigen dan $\mathrm{pH}$ tidak diimbangi dengan penurunan ion-ion mineral yang terdapat dalam limbah. Penurunan ion mineral ini tidak berbeda nyata. Mineral-mineral nitrat, fosfat dan kalium sangat dibutuhkan oleh mikrobia untuk melaksanakan aktivitas kehidupan, baik untuk metabolisme maupun penyusun tubuh. Keberadaan dalam limbah tidak terlalu besar, dan masih digunakan oleh mikrobia, maka ion-ion tersebut hanya berputar dari sel hidup lalu mati. Sel yang telah mati diuraikan dan melepas ion-ion tersebut yang akan digunakan lagi oleh sel yang hidup (Diver, 2001). Hal ini berpengaruh juga dengan 
nilai kekeruhan maupun partikel endapan zat tersuspensi (TSS) yang juga tidak berbeda nyata.

Selain kurang mampu dalam mengurangi kandungan ion-ion mineral, $\mathrm{EM}_{4}$ juga membutuhkan waktu yang cukup lama yaitu 6 hari untuk menurunkan BOD dan COD. Hal ini dirasa kurang ekonomis bagi dunia industri, karena lamanya waktu proses akan membutuhkan biaya dan tempat yang besar. Apalagi limbah yang diproduksi terus bertambah setiap saat. Oleh karena itu, di dalam usaha memanfaatkan $\mathrm{EM}_{4}$ untuk mengolah limbah cair ini masih perlu diteliti lebih lanjut, terutama terkait dengan lamanya waktu tinggal atau waktu proses dan kemampuannya dalam mengurangi ion-ion anorganik serta padatan tersuspensi. Ini merupakan kendala umum yang terjadi pada penggunaan mikrobia sebagai agen remidiasi (Balba et al., 1998).

Berdasarkan hasil di atas maka dapat disimpulkan bahwa kemampuan $\mathrm{EM}_{4}$ dalam mengolah limbah spiritus hanya mampu menurunkan kebutuhan oksigen (BOD dan COD) dan $\mathrm{pH}$, namun tidak mampu menurunkan kandungan ion-ion mineral.

\section{Daftar Pustaka}

Balba, M.T., Al-Awhadi, N. and AL-Daher, R. 1998. Bioremidiation of Oil Contaminated Soil: microbiological methods for feasibility assesment and field evaluation. J. of Microb. Methods 32: 155-164.

Diver, S. 2001. Nature Farming and Effective Microorganisms, Rhizophere II. http:// www.emtrading.com. 10/24/2004.

Eweis, J.B., Ergas, S.J., Chang, D.P.Y. and Schroeder, E.D. 1998. Bioremidiation Principles. Mc Graw Hill Inc. USA.

Pratiwi, D.L. 2003. Dekomposisi Limbah Cair Menggunakan Lumpur Aktif dengan Penambahan N dan P. Skripsi Fakultas Biologi Universitas Atma Jaya Yogyakarta.

Sulia. 2003. Biokontrol dan Bioremidiasi. Penerbit UPN Veteran Yogyakarta.

Sudirdjo, Marsoedi dan Anik, M.H. 2001. Efektivitas Bakteri Super- NB Mengendalikan Laju Akumulasi Bahan Organik da Kualitas Air Media Budidaya Udang. Laporan Penelitaian Fakultas Pertanian Universitas Brawijaya Malang. Tidak diterbitkan.

Szymanski, N. dan Peterson, R.A. 2003 Effective Microorganisms and Waste Water System in Future Directions for On-site System. University of New England. http://www.royacagol.ac.uk/research/confere nces. 10/02/2004 